Research Article

\title{
The experience of attunement and misattunement in dance movement therapy workshops
}

\author{
Tjaša Jerak ${ }^{\mathrm{a}}$, Alenka Vidrih ${ }^{\mathrm{a}}$, Gregor Žvelc ${ }^{\mathrm{b}, \mathrm{c}, \mathrm{d}, *}$ \\ ${ }^{\text {a } U n i v e r s i t y ~ o f ~ L j u b l j a n a, ~ F a c u l t y ~ o f ~ E d u c a t i o n, ~ A r t s ~ T h e r a p i e s ~ P r o g r a m, ~ P r i m a r y ~ S c h o o l ~ S a v s k o ~ N a s e l j e, ~ L j u b l j a n a, ~ A r t+, ~ I n s t i t u t e ~ f o r ~ D e v e l o p m e n t ~ T h r o u g h ~ C r e a t i v i t y, ~}$ \\ Slovenia \\ ${ }^{\mathbf{b}}$ University of Ljubljana, Faculty of Arts, Department of Psychology, Slovenia \\ ${ }^{\mathrm{c}}$ University of Primorska, UP FAMNIT, Department of Psychology, Slovenia \\ ${ }^{\mathrm{d}}$ Institute for Integrative Psychotherapy and Counselling, Ljubljana, Slovenia
}

\section{A R T I C L E I N F O}

\section{Keywords:}

Dance movement therapy

Attunement

Kinesthetic empathy

Qualitative research

\begin{abstract}
A B S T R A C T
Moments of attunement and misattunement were explored in a dance movement therapy workshops. The guiding question was; "how do participants experience moments of attunement and misattunement in dance movement therapy workshops?" The study employed a quasi-experimental design, with phenomenological inquiry, including a two part analysis: Laban Movement Analysis and descriptive grounded theory using coding. Four students of expressive arts therapies attended four experimental dance movement therapy workshops, emphasising the process of mutual attunement. All workshops were video recorded. Based on video movement analysis, key moments of nonverbal attunement and misattunement were selected, and then analyzed within group interviews with participants. The results of the study show that successful attunement in dance movement therapy draws the client's attention to the present moment; it encourages individual spontaneity, playfulness, and creativity; promotes embodiment, and thus the integration of mind and body. Successful attunement to the other leads to an intersubjective interchange, where two people co-create an intersubjective experience. Successful attunement to the group leads to the experience of oneness with the group. Moments of misattunement trigger unpleasant feelings, and result in a lack of spontaneity, feelings of exclusion, and hinder contact. The limitations of the results should be considered, as the study was done on a small number of participants and in nonclinical experimental setting. Researchers propose a larger study with clinical populations to further investigate the phenomenon of attunement and misattunement in dance movement therapy.
\end{abstract}

\section{Introduction}

Kinesthetic empathy is a core concept in dance movement therapy (Behrends, Müeller \& Dziobek, 2016; Fischman, 2009; Tortora, 2006). Broadly speaking kinesthesia can be understood as sensation of movement and posture (Reynlods, 2012), and empathy as the ability to understand and respond to somebody else's inner experience (Decety and Jackson, 2006). Kinesthetic empathy is therefore seen as the ability to understand somebody else's inner experience through body movement sensing (Lieberman, 2007; Rova, 2017). Dance movement therapy (DMT) is based on kinesthetic intersubjectivity. The therapeutic relationship is formed through movement and dance (Payne, 2006; Payne et al., 2016). The therapist uses his/her own bodily movement "to meet" the client where he or she is, through his/her movement patterns. In this somatic relationship, the therapist connects with the client's movement patterns and mirrors them back to him/her with attuned movement patterns (Samaritter and Payne, 2013; Payne et al., 2016). Dance movement therapy is a therapeutic modality, in which the therapist interprets the client's movement and uses kinesthetic empathy to form an understanding of the client's inner state. Kinesthetic empathy has played a crucial role in DMT since its beginnings, and is considered to be one of the most important dance movement therapy contributions to psychotherapy by some authors (Fischman, 2009; Behrends, Müeller \& Dziobek, 2012).

From a phenomenological perspective on embodied cognition, the mind is not simply reduced to brain processes in the head, but is distributed across the brain, body, and environment (Gallagher, 2005; Gallagher and Payne, 2015). Dance movement therapy focuses on movement analysis and the idea of changing movement, which directly affects changes in cognition and emotion (Payne et al., 2016; Koch, 2006; Fuchs, 2009). Embodiment supports the idea of unity of body and mind, and the reciprocal influence of body attitudes and emotional and

\footnotetext{
* Corresponding author at: University of Ljubljana, Department of Psychology, Aškerčeva 2, 1000 Ljubljana, Slovenia.

E-mail address: gregor.zvelc@guest.arnes.si (G. Žvelc).
} 
cognitive states (Koch et al., 2017). The infant and mother's first communication also occurs through movement (mimics, locomotion, etc.) (Stern, 1985). Kinesthetic attunement therefore imitates an important psychological developmental process - nonverbal attunement in early childhood, through which the infant forms its first perceptions and is therefore the primary language through which a person learns to understand himself and others (Behrends, Müeller \& Dziobek, 2016). Trevarthen and Fresquez (2015) see attunement as an aspect of kinesthetic empathy, which "involves matching some qualitative aspects of a movement without reflecting it exactly" (p. 201). Its purpose is to bring people into a harmonius, responsive relationship (Trevarthen and Fresquez, 2015). Erskine and Trautmann (1997) describe attunement as a two-part process: "the sense of being fully aware of the other person's sensations, needs, or feelings and the communication of that awareness to the other person" (p. 90). Attunement in this way goes beyond empathy - it provides a reciprocal affect and/or resonating response. As Deveraux (2017) puts it, successful attunement leads us to feel understood and safe and thus ready to connect with each other. It is a complex social phenomenon and "it is the situatedness within the interaction that determines whether an action is attuned to another person or not." (Samaritter and Payne, 2017, p. 2). The inability to experience relational attunement, a "mismatch" in trying to attune, can be taught of as misattunement (Kossak, 2009). Referring to early childhood development, Stern (1985) makes a distinction between "purposeful misattunement" and "true misattunement". Purposeful attunement is when the mother is intentionally overmatching or undermatching the infant's behaviour, in a desire to increase or decrease the baby's level of activity or affect. In contrast to that, true misattunement occurs when the mother incorrectly identifies the infant's feeling state or is unable to find it in herself. According to Kossak (2009), misattunement (in a safe environment) may be an important stage of psychological development, leading to new awareness and integration of new reactions. While it can make a client feel uncared for or unsupported, learning to deal with it in a constructive way, can help individuals with accepting and coping with misattuned moments in real life (Kossak, 2009).

Mirroring is a method with which an individual can move from merely attending to and understanding the other's experience to a point where he/she can actually experience similar intentionality and emotions by imitating his/her movement qualities. McGarry and Russo (2011) describe that "mirroring occurs when two people make similar body movements that are coordinated or slightly echoed in time" (p. 178). A DMT therapist can mirror exact movements of the client or just certain movement qualities, especially effort elements, which reflect the movement's emotional tones. For example, if a client is moving with a fatigued posture, the therapist can imitate the quality of "fatigue." The DMT therapist, who is trained in movement analysis, selects movement qualities that reflect the quality of the client's mood (McGarry and Russo, 2011). Sometimes the client may not even be aware of the fact that the therapist is imitating his/her movements, and the therapist may deliberately begin to exaggerate in certain movements in order to increase the client's awareness (Berrol, 2006).

Mirroring is a dance movement therapy method, used to open the possibilities for embodied intersubjective attunement. Succesful mirroring leads to increased attunement (Eberhard-Kaechele, 2012), but despite its widespread use in dance movement therapy practice, there is a lack of research on the effects of it. The results of studies, conducted mostly in other areas of psychotherapy, are promising and show that mirroring increases empathy between the therapist and the client, as well as between clients (Berrol, 2006). A recent study by Koch et. al. (2017) shows that mirroring in dance movement therapy brings improvement on intersubjective empathy and supports wellbeing in patients with schizophrenia.

In DMT, mirroring takes place in the context of a secure therapeutic relationship. Neuroscience research provides the evidence that individuals in a trusting relationship are more likely to engage in mimicry of each other's movements to enhance their understanding (Behrends,
Müeller \& Dziobek, 2016; McGarry and Russo, 2011). Synchronisation may align the person to the rhythm and movement of the other, and also to his/her affective dynamics and intentionality (Rabinowitch et al., 2012).

Empirical evidence for the existence of kinesthetic empathy is offered by research on mirror neurons (Behrends, Müeller \& Dziobek, 2016). Mirror neurons are a type of neurons that respond equally if we perform a certain action, or if we only observe it. They were first discovered in a study of the motor cortex of macaque monkeys. It was around 1990 when Italian neuroscientists stumbled upon the discovery that identical neurons were activated in the monkey which handled with an object (a peanut), as were in the second monkey, which was only observing the action (Gallese, 2003). It was proposed that mirror neurons may constitute a neural mechanism enabling implicit action understanding (Gallese, 2003). The following studies of mirror neurons with humans found that the activation of mirror neurons creates a neural picture of the mental state of another person. Observing the foreseeable actions of another person therefore results in the creation of his mental scheme. This implicit, automatic, unconscious process enables the observer to "grasp" the world of another pre-reflexively (Gallese, 2005). Choreographer and dance pedagogue Susanna Leigh Foster (2011), who has studied kinesthesia in relation to empathy and perception, sums up Gallese's findings when she argues that observation of movement can arouse a so-called psychic resonance, an internal motor image in the observer. This resonance (which could be described as an internal simulation of the observed movement) is responsible for our ability to predict the actions of others and the consequences of our movement. Research on mirror neurons suggests that the brain is able to simulate a particular movement, and from this simulation, to select the most appropriate response. The prediction of the movement of others arises from a visual perception that activates the pre-motoric areas of the brain, which in effect causes the observer to react as if he/ she were in motion. The frequency of observed motion sequences present in the sociocultural environment determines the preferred paths of inference/ predicting movement (Gallese, 2005). Embodied simulation is modulated by our own personal history, by the quality of our attachment relations, and by our sociocultural background (Gallese, 2003).

DMT sessions are most usually accompanied by music. Moving to music can facilitate temporal coordination of two or more people, which enhances their chances for succesful mirroring. Areas of the brain, involved in beat perception, overlap with movement production brain areas, and people have a propensity to move in coordinated time with external rhythm (McGarry and Russo, 2011). Music, which has been shown to elicit strong emotions, can be used as a tool for induction of emotions, especially with emotionally inhibited clients (McGarry and Russo, 2011).

This qualitative study was designed to investigate the moments of attunement and misattunement in dance movement therapy workshops. The key research question was how do participants experience moments of attunement and misattunement to other participants in dance movement therapy workshops?

\section{Background of the study}

Four students of Expressive Arts Therapies (including the first authour of the research) conceived the idea of an experimental laboratory of dance movement therapy. In the framework of the experimental laboratory - entitled "What can a Body Do?" - they arranged for regular meetings in a one-year period (every 14 days) with the intent to try out a number of theoretical starting points in dance movement therapy by doing experimental work. In the experimental laboratory, the first author of the research led four workshops of dance movement therapy, where the greatest focus was on the process of mutual attunement. Each workshop was structured with an inital warm-up, breathing and body awareness exercises, followed by a main theme leading to dance- 
movement improvisation and final closure. The main dance movement therapy methods used were: mirroring, synchronised movement and contact improvisation. We mainly used group techniques: interaction in pairs and interaction in groups. Workshops lasted from 60 to $90 \mathrm{~min}$ utes, and were recorded with a video camera.

\section{Method}

\section{Participants}

We used convenience sampling in the study. The participant sample of the study covered four research participants, three women (including the first author of the research), and one male, in the age range of 29-38 years. All participants were students of Expressive Arts Therapies. The average age of participants was 32.3 years. All four participants have a university degree, three were unemployed during the study, one of them was regularly employed. At the time of the study, they had all been studying in the masters program Expressive Arts therapies at the Faculty of Education in Ljubljana, for 1-2 years. Three participants are Slovenians, and one participant is from Argentina.

\section{Instruments}

The Attunement/Misattunement Observational Checklist was developed to guide the researcher's observations in a video movement analysis. The checklist is based on the Movement Signature Impressions Checklist, by Suzi Tortora (2006). Its goal is to create as exact and accurate a description of movements as possible, and to define moments of attunement and misattunement in embodied interactions, using movement analysis. Movement is observed according to four categories derived from using Laban movement analysis: body, shape, effort, and space (Laban, 2002). By using the Attunement/Misattunement Observational Checklist we were able to determine the moments of attunement, when participants were responsively duplicating movement qualities between themselves and moments of misattunement, when there was a mismatch in their movement qualities. The identified categories of (mis)attunement refer either to moments of (mis)attunement in time (speed, rhythm, duration), space (pathway), energy (weight, flow), physical contact to moments of intersubjective emotional regulation.

The interpersonal process recall interviewing method (IPR) (Kagan, 1974) is a method of qualitative interviewing intended for a detailed analysis of interpersonal interactions. It uses video-assisted recall to access conscious, yet unspoken experiences, as they occurred in the time of the interpersonal interaction under investigation (Larsen et al., 2008). A typical IPR application involves video recording an interaction, which is then viewed by the participants with a research interviewer. During the interview the participants are asked to recall their thoughts, feelings, and sensations as experienced during the session, without encouraging critique or self-confrontation (Larsen et al., 2008). IPR interviews usually take place within $48 \mathrm{~h}$ after the video recorded session. In practice, it is not uncommon to investigate the participant's experience after longer interval periods - a week, a month, and even a year after the session under investigation (Larsen et al., 2008). During IPR interviews, participants often become curious explorers of their experiences. They reflect and comment on the process and work with the interviewer to make their implicit experiences explicit through interview conversation (Larsen et al., 2008). One of the key differences between IPR and other methods of interviewing is the fact that IPR focuses on process rather than on content. It attempts to access the participant's inner thoughts, feelings, and bodily sensations. The interviewer might ask questions as: How did you feel when...?

\section{Procedure}

The first author of the research led four workshops of dance movement therapy, where the focus was on the process of mutual attunement. Workshops lasted from 60 to 90 minutes, and were recorded with a video camera. The video movement analysis was made, defining the moments of attunement/misattunement on the basis of The Attunement/Misattunement Observational Checklist. Each workshop was followed by a group interview, based on the interpersonal process recall method. Interviews were conducted on average 10 days after the workshops, and lasted approximately one hour. The videos were viewed on a 15.6-inch computer screen. In the group interviews, we focused the attention of the participants on the description of moments of attunement and misattunement, which we previously identified with video movement analysis. The video was stopped at the selected excerpts and viewed again as many times as needed. Group interviews were audio recorded, and transcripts of the interviews were made. Qualitative analysis was made included coding techniques from the grounded theory research method (Corbin and Strauss, 2015). We began the analysis after completing and transcribing the first interview. We analyzed each interview by open coding. In the first phase of open coding, codes or units of meaning were identified. Open coding resulted in codes of different level of abstraction. Some of the codes we identified were: »integrity«, »feeling connected with the other«, »withdrawing from contact«, »time consistency«, »rhythmic consistency«, »breathing together«, »contact limitations« etc. All the text segments from the proceeding interviews that shared the same characteristics were given the same code. After completing with open coding of all four interviews, 164 codes were identified. In the second phase of axial coding, we grouped together similar codes into categories that shared basic characteristics. For example, we grouped codes: „to merge together", »common energy«, »exchange«, »flow of energy« into the category »intersubjective interchange». After asigning the categories, relations within specific categories were established as well as the relations between a category and the codes, assigned to the category. Continuing with constant comparative analysis, we could determine main categories and subcategories, based on their level of importance and the frequency with which the experience was mentioned. The wider the area they covered, the higher was their level of importance. This process resulted in 6 core categories and 10 subcategories. In the phase of selective coding, the data was unified around core categories, and described within two domains of experience: "experience of attunement" and "experience of missattunement". The data was analyzed using a software program for qualitative analysis, ATLAS.ti 7.

\section{Results and discussion}

On the basis of the Attunement/Misattunement Observational Checklist 16 moments of attunement and 6 moments of misattunement were selected for further analysis: 3 moments of attunement and 3 moments of misattunement in time, 3 moment of attunement and 2 moments of misattunement in space, 6 moments of attunement and 1 moment of misattunement in energy, 3 moments of attunement in physical contact and 2 moments of intersubjective emotional regulation. Sometimes it was difficult to determine the type of (mis)attunement, because very often (mis)attunement, occurred on several different levels at the same time. For the needs of the study, the moments were attributed the type of (mis)attunement which, in our opinion, prevailed in the movement analysis. Intersubjective emotional regulation was thus definitely the least chosen type, since it was difficult to objectively determine it through movement analysis alone. In group interviews, we avoided the categorization of (mis)attunement altogether and we talked only about moments of attunement and misattunement. We would like to emphasize the fact that different types of attunement do not exclude each other.

Table 1 shows results of qualitative analysis of participants' experience of attunement and misattunement in dance movement therapy workshops. 
Table 1

Experience of attunement and misattunement in Dance Movement Therapy workshops.

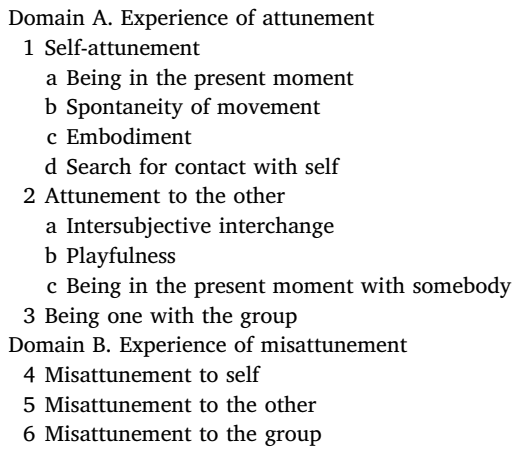

\section{Domain A. Experience of attunement}

Experience of attunement includes three main categories: self-attunement, attunement to the other, and experience of unity with the group.

\section{Self-attunement}

Participants connected the experience of self-attunement to the absence of thought and being in the present moment, with spontaneity of movement and embodiment.

Being in the present moment. Participants described the present moment as absence of thought and aliveness. In these moments they were not burdened with their surroundings, or with their thoughts, and enjoyed the simplicity of being. The following quotes illustrate how moments of absence of thought contributed to the feeling of pleasure and wholeness.

"Empty, empty head, without expectations, it just happened. I experienced complete joy, with an empty head. It was very nice. I felt attunement, not only within us, but also with myself. Complete attunement. I do not have all the words to describe it. You just are. In that moment you are full. And you can exchange, because you are full. "/ ... /" I was simply here. I was in the moment." 2: 9

"I was without thought. . . That's when you feel that you are whole, that you're living. Such a flow of energy, a great feeling, no thought about what will be your next move, and everything flows out of you. ..." 2: 6

Segal, Williams and Teasdale (2002) distinguish two modes of mind: "being" and "doing". The "doing mode "is focused toward change, while the "being mode "is focused on accepting and allowing what is, without pressure to change anything. We believe that the participants' experience was related to this state of mind. Stern (2004) defines the present moment as a directly lived story of the now - we experience it as it is happening and the experience is not distanced by language or abstract explanation. In these moments participants were without expectations and doubts and could completely let themselves free to the dance in relation to the other. These moments were experienced as short lived. Stern (2004) describes moments of the present moment that last for a few seconds, more precisely between 1 and $10 \mathrm{~s}$, and on average 3-4 s. This is the time needed for us to be able to meaningfully distinguish the content we perceptually perceive in the behaviour/expression of other people, to respond to it, and become aware of it (Stern, 2004).

In our study, the participans' experience of the present moment was connected with either self-attunement, attunement to the other or attunement to the group. The participants explained that they could experience several levels of attunement at the same time, or their experience shifted from one level of attunement to another.

Spontaneity of movement. Participants described spontaineity as being able to listen more closely to their inner impulses and to express them freely in front of the others. One of the participants described in detail how spontaneity of the movement was due to the deep awareness of the internal impulses.

"This feeling when you begin to move unconsciously, that is - it's really freedom for me." 2:25

"I just wanted to give in to dancing, not thinking about what should I do, what kind of a move. . . Sometimes I felt only my finger and I moved it. Not that I would not want to move my hand, but at a certain moment it was this kind of impulse, a move, and then it slid further." 2:24

When the participants managed to silence the conscious control of their movement and "gave in to the dance," they could, in their own words, express themselves more freely. When they reached a certain level of trust and relaxation in movement with another or within the group, they dared to listen more closely to their inner impulses and expressed them in front of the others. This gave them a feeling of liberation. One of the participants described how she was focused on the present moment and on the impulses that her body gave her (embodiment). Kipper, Green, and Prorak (2010) mention this kind of deep focus as they characterize spontaneity as a source of self-awareness and self-reflection. They also connect spontaneity with free experimentation and intense concentration on the task. In conjunction with spontaneity, participants most often described how they allowed themselves to be free in dance, and explored their movement and movement with other participants. Such free experimentation led them to new experiences and to contact with others.

Embodiment. Furthermore, attunement to self was described as an experience of embodiment, where participants experienced unity of mind and body. The participant in her spontaneous movement experienced the absence of perceptible boundaries between the mind and the body. She expressed it with a metaphor, "that she was no longer in her head," but "in her body, with all her being" (1: 12). We can connect her experience with phenomenologically-oriented views of embodied cognition which emphasize the idea that the mind does not only exist in the mental processes in the head, but is distributed between the brain, the body, and the environment (Gallagher and Payne, 2015; Koch, 2006). The idea assumes that the mind is always embodied - through sensomotor activity - and that it is intertwined with the physical environment surrounding it. When we listen to what the body tells us, we, as the participants described it, are more in contact with ourselves. Through embodiment - focusing on the body and on body impulses and physical communication with others - we experience integrity.

Search for contact with self. In conjunction with self-attunement, the participants described a process of searching for contact with self, specifically in situations where their need for self-attunement overtook the need for attunement with others. When the participants withdrew from contact with others, they closed their eyes and listened to their inner impulses, and by doing this they deliberately put their needs before the needs of others. A very illustrative example is the example where the participant who wanted to dance with another, also felt the need to seek contact with herself, which ultimately prevailed.

"When I was leading the movement, I was paying attention to how she was following me. Sometimes I even began to move more slowly, because I was aware of the fact she couldn't follow me/ ... / At the same time, I wanted to avoid this feeling because I wanted to move freely... So, I closed my eyes in the middle of it, only to free myself from this feeling." 2: 3

The search for contact with self can be connected with the concept 
of internal contact, which Erskine, Moursund, and Trautmann (2013) define as an individual's full awareness of one's own feelings, needs, thoughts, sensations, and fantasies. Participants looking for more indepth contact with themselves wanted to get in touch with their inner experience and to become more fully aware of it.

\section{Attunement to the other}

Attunement to the other is the second main category of the experience of attunement. Attunement to the other consists of the following subcategories: intersubjective interchange, playfulness and being in the present moment with somebody.

Intersubjective interchange. The subcategory intersubjective exchange refers to the process of spontaneous interchange of movement in which the participants exchanged as the initiators of movements. In these moments participants experienced as if they and their dance partners were intertwined. In the interviews, they reffered to the exchange with terms as "energy exchange," "energy flow," and "being merged."

"It happened spontaneously. I was without thought. . . I realize that for a while I was following her movements, and then she was following mine, but it was as if these movements were going on between us. As if they were not hers, nor mine, but ours." 2: 17

"It seemed to me that even though you were leading the movement, you were also receiving from me. . . Because you began to emphasize certain movements, after I had mirrored them from you. We had this echo going on - giving, receiving." $3: 1$

Referring to the "intersubjective interchange," the participants described that they were no longer completely alone in leading their movement, but rather felt that they and their dance partners were alternately guiding the movement. In this context, "movement" refers to two phenomenas - to the movement of each individual and to a joint movement in the duet. The process of creating an intersubjective experience is best illustrated by the description of the experience of one of the participants, who explained that she began to emphasize her movements more when she saw them on the other participant. She trusted her more, and because of this, she wanted to emphasize certain segments of her movement more and experiment with them.

"/ ... / When I saw how the movement looks like, I emphasized it even more and experimented with it a little more. I dared to cross a border, which I would otherwise not have. It seemed to me to like we were co-creating, I did not feel like I was the only one leading./ .../" 3: 2

In the light of the intersubjective theory, the interchange - as decribed by the participants - can be seen as an intersubjective field, a system in which psychological phenomena are formed between reciprocal mutual influence of subjective worlds (Stolorow, Brandschaft \& Atwood, 1992). An intersubjective field is a dynamic system that creates both intra and intersubjective experiences, through an embodied emotional experience (Avila, 2014). When two people co-create an intersubjective experience, the experience of one overlaps with the experience of the other. The person experiences his/her experience, and at the same time he/she experiences the experience of the other - as he/ she perceives it through non-verbal observation (Stern, 2004). Stern (2004) argues that an intersubjective encounter in which a person creates an intersubjective experience can only occur in the present moment. An individual integrates his/her experience - what he/she is experiencing at the present moment and what he/she perceives is experienced by others - if both occur simultaneously and become part of the same association structure. This structure becomes part of a common intersubjective experience. Being in the present moment with somebody is a prerequisite for this "exchange", as one of the participants explained.
Playfulness. Furthermore, attunement to the other was described with feelings of playfulness. Some participants experienced dance improvisations in diads as a co-creation game, and expressed their feelings of being like a child in play. While watching her movement on video, one of the participants began to giggle and said

"I was like a child!" 3:31

The sense of playfulness, as expressed by the participants, appeared after a certain time of attuning and was associated with the possibility of actively experimenting with the course of events, for example, in the reciprocal interchange in dance. This exchange took place when both of the participants had the feeling that they were exchanging in the leading of the movement, and were therefore alternately leading and following the movement. When the participant became playful, she/he studied the movement of her/his dance partner or tried new ways of movement, with lightness and openness toward the new movement. The sense of playfulness brought pleasure to the participants.

Winnicott (1971) argues that a person can be creative and use his whole personality only through play. Only by this a person can discover his true self. Summing up the participants' citations, we can conclude that dance movement therapy promotes playfulness, which according to Winnicott is the starting point for any therapeutic work. Associated with the feeling of care and trust (in a therapist, a friend), the person exits as a whole, and does not respond with his/her defense mechanisms.

Being in the present moment with somebody. The experience of attunement to the other was very often intertwined with the feeling of self- attunement and the feelings of absence of thought and being in the present moment. In dance improvisation the participants were untroubled (without expectations, doubts) and completely let themselves free to the dance in relation to the other.

"And I was in the moment, with somebody." 2: 31

"As if I was in another state, unburdened by the surroundings, not with what will be my next move, not with how I breathe, and how I look. . . So, I was here. I was in the moment." 2: 18

When the participants were relieved from their doubts and expectations, they were present in the relationship in the present moment. One of the participants described it even as "being in another state." Another participant described the feeling of fulfillment that took over her and linked it with the spontaneity of movement and the interchange. She described being in the present moment as a condition to "exchange" in a relationship. These moments of attunement were perceived as short and fleeing.

"These moments of attunement came spontaneously. A couple of seconds and that's it. And again, there was movement, repetition, and in a moment came the true attunement - this connection." 3: 14

\section{Being one with the group}

The third main category is "being one with the group". This category refers to a sense of attunement to the group, in which participants experienced as if the boundaries between experiencing themselves, their bodies and the bodies of others were erased. In this way they had the feeling that they were "as one".

"It was not - I'm moving, you're moving, but - we're moving. . . / Maybe it was transcendence. . . / . . / I felt connection with the group, with the other and with myself. Everything was one. And everything was good."1: 12

The participants felt that the movement was going spontaneously between them and not that it was being directed by anyone. The participant, who described the experience of "transcendence," remarked that she experienced connection with each individual, with the entire group and with herself. The participants described the experience of 
unity as "being as one" (1:13) and "everything was one." (1:12) They felt that they were no longer separated and that they "were breathing together" (1:14) in dance.

The participants' experience can be described as the phenomenon of merged intersubjectivity, a relational field in which a group of individuals shares their experience: intent, emotions, and certain cognitive processes. Rabinowitch, Cross, and Burnard (2012) describe it on an example of a group of individuals who co-create music (for example, a music jam session). Continuous and mutual adjustment to another person's pace and rhythm, in a musical jam session, may align affective dynamics and intentionality (Rabinowitch et al., 2012). The various elements that constitute a musical jam session are similar to, or even more fully represented in a group movement improvisation. Synchronous movement is a method with which an individual can move from merely attending to and understanding the other's experience to a point where he/she can actually experience similar intentionality and emotions by imitating his/her movement qualities. In addition to all the elements of alignment described above (movement observation, synchronous movement, creation of a trusting environment, non-verbal communication), group movement improvisations often included touch. When the bodies of the dancers are so profoundly listening to one another, while at the same time being in physical contact, each feeling of self is at the same time a response to the feeling of the other. Since in group dance improvisation we are already focused on experiencing the experience of others, it is not surprising if the boundaries of our experience fuse with the experiencing of group movement that takes place in a certain rhythm and pace. Even though the participants' experienced states of merging with the group, their sense of individuality remained. As Karkou and Joseph (2017) point out, sharing one rhythm can enable individuals to join together as one group, defining a clear sense of physical separateness, finding both their identities as individuals and within the group.

\section{Domain B. Misattunement}

We classified moments of misattunements into three main categories: misattunement to self, misattunement to the other and misattunement to the group. Misattunements took participants out of the present moment, which showed in less spontaineity, self-censorship of movement, negative emotions and experiences of exclusion from the group. Erskine et al. (2013) describe contact as a state of being aware of inner wants, needs, perceptions, emotions, or thoughts of self, and simultaneously being aware of what and who is in the environment. Contact is enabled when a person is fully present - attuned to his/her inner experience. In moments of misattunement participants lost contact with self and/or other. Participants described that moments of misattunement with self were closely related to misattunements to the other. Both experiences showed in feelings of costrainment and selfcensorship of movements. Movement expression became less spontaneous, more consciously controlled and uncoordinated. One participant described misattunement with self as unalignment with her real feelings. In moments of misattunements participants were preoccupied with their thoughts about self or others and experienced the loss of being in the 'now'.

\section{Missattunement to self}

Attuning to others often led to a sense of greater self-attunement, but sometimes it prevented it too. This happened when attention to the other evoked the feelings of fear, doubt, and insecurity. In these moments, movement expression became less spontaneous, more consciously controlled and uncoordinated.

"I was forcing my movements, something I was not." 3: 3

"I felt it in my movements. They were not so relaxed, and I wanted something more, something different. They were not alligned with me. They were more controlled, less spontaneous. And when I stopped focusing on these thoughts, the true movement came out again. That spontaneous one - we are here, we are together, this is ours. ..." 3: 4

The participant described how she was self-censoring the movement that emerged because of her own doubts, perhaps fear, and how she began to control and consciously direct it. For this reason, her movement became less flowing, and unaligned with her real inner feelings. This mismatch brought her dissatisfaction.

The participant actually described the absence of spontaneity of movement. Barriers to spontaneity were problems with self-esteem the participant worried about what others think of her, she was worried that the other participant was "already bored," and so forth. The participant felt that she was not a good dancer - as she repeatedly pointed out in the interviews. When these feelings and thoughts overwhelmed her in dance improvisation, she started to consciously direct her movement. In the example mentioned above, experiencing misattunement to self was connected with experiencing misattunement to the other.

\section{Misattunement to the other}

Participants linked the experience of misattunement to the other with the feelings of doubt and fear that led to disharmony in the body, as well as with the feeling of restricting their own movement expression. As mentioned earlier, attention to the other sometimes evoked the feelings of fear, doubt, and insecurity. In these moments, the participants no longer felt attunement to the other, nor self-attunement. The participant described her conflicting feelings as follows:

"There were two poles in me. The moments I enjoyed when I was unburdened and the moments when I worried, what if it was already boring, and, I need to do something new. Some kind of disharmony appeared in me. ../" 3: 2

"Because of this fear of being boring, and of wanting something different, I felt as if I was not experiencing the movement as it was happening, the dynamics, as if I was not letting it out, instead I interrupted it and tried something else. . /" $3: 3$

The participant in the relationship was no longer in the moment and as she describes herself, her movement became more consciously controlled and less relaxed. She described her experience of misattunement with the other as "forced movement" and "disharmony." As she explained later, experiencing these moments of misattunement were much more intense than experiencing a spontaneous attuned exchange in dancing. When the participant, in the course of subsequent exercises of attunement, felt more relaxed and trusted her dance partner more, moments of "disharmony" diminished.

When describing their experience of misattunement to the other, the participants also described feelings of constrainment. They felt constrained when they themselves searched for more in-depth contact with themselves, and their need for self-attunement overtook the need to attune to others. Since they wanted to completely let themselves free to the inner impulses in dance, they felt that the attention to the other in movement improvisation was limiting them in their free movement expression.

"I could describe this as a kind of tension. . . Because you had to be very careful about the other. . . If I compare it to the previous exercise where you were in your own rhythm, and you did not have to think about what the other would do. ..." 2: 10

"I had a feeling I could let myself go even more. I was cautious. ..." 3: 7

"Sometimes it happened that I consciously started to move slower so she could follow me. I did not want to be unsuccessful in mirroring, attuning, and at the same time, this feeling was burdening me, because I wanted to move freely. So I closed my eyes in order to relieve myself of this feeling. I did not know how to do it otherwise. . ." 3: 8

The last quote describes the participant's purposeful misattunement 
to her dance partner - she closed her eyes to relieve herself of the negative feeling.

\section{Misattunement to the group}

Participants experienced misattunement with the whole group as well, which evoked negative feelings and feelings of exclusion. One of the participant reported feeling excluded because she could not connect with the group:

"I pulled back here. It was hard for me. I stayed in myself and I was no longer connected with the group. ..." 4: 8

Empirical psychological research shows the connection between synchronous movement of the group and the feeling of belonging and cooperation (Behrends et al., 2012; Valdesolo et al., 2010). Just like the phenomenon of imitation, which refers to a person's inclination to interact with another unconsciously by imitating the gestures, the pose and the speech of another person, synchronized movement serves a very important communication task, that is social integration (Behrends et al., 2012). When experiencing misattunement to the group, the participant felt the exact opposite, which is the feelings of exclusion.

\section{Conclusion}

In dance movement therapy, kinesthetic empathy is viewed as a catalyst for positive change in the client, but in practice it is still a very poorly understood phenomenon. Results of this study indicate the rich possibilities for achieving a deeper understanding of moments of attunement and misattunement in dance movement therapy. Non-verbal attunement in dance movement therapy allows the client to express himself, and enables him to have new responses, leading to the development of richer, deeper interpersonal interactions. The results of this study show that successful attunement in dance supports being in the present moment. It promotes individual's spontaneity, playfulness, and creativity, it stimulates embodiment and thus the integration of the mind and body. It can also lead to the experience of an intersubjective exchange where two people co-create an intersubjective experience. Successful attunement to the group leads to the experience of being one with the group. Moments of misattunement trigger unpleasant feelings, and result in lack of spontaneity, feelings of exclusion, and hinder the contact.

Some limitations of the present study can be pointed out. Attunement/Misattunement Observational Checklist was used to determine the moments of (mis)attunement. The checklist is in preliminary phase of development and there is no data on its reliability and validity. The workshops were run as experimental workshops focused on the process of mutual attunement. Participants were students of expressive arts therapy and the main researcher was leading the workshops. This context could have had an impact on the dynamics of the group and research results. With this approach we gathered information regarding participants' experience of attunement and misattunement in the group, however results cannot be generalised to dance movement therapy sessions with clients. There is a need to look at actual dance movement therapy sessions in the future and explore whether the findings remain relevant in a clinical context. So the present study should be considered as a developmental study that could be repeated within clinical context with a larger sample of participants.

\section{Funding}

This research did not receive any grant from funding agencies in the public, commercial, or not-for-profit sectors.

\section{Declaration of conflicting interest}

We declare no potential conflicts of interest with respect to the research, authorship, and/or publication of this article.

\section{References}

Avila, A. (2014). The intersubjective: A core concept for psychoanalysis. International Forum of Psychoanalysis, 25(3), 186-190. https://doi.org/10.1080/0803706X.2014. 967813 Retrieved from.

Behrends, A., Müller, S., \& Dziobek, I. (2012). Moving in and out of synchrony:A concept for a new intervention fostering empathy through interactional movement and dance. The Arts in Psychotherapy, 39, 107-116.

Behrends, A., Müller, S., \& Dziobek, I. (2016). Dancing supports empathy: The potential of interactional movement and dance for psychotherapy. European Psychotherapy 2016/ 2017: Embodiment in Psychotherapy, 13, 99-131.

Berrol, C. (2006). Neuroscience meets dance/movement therapy: Mirror neurons, the therapeutic process and empathy. The Arts in Psychotherapy, 33(4), 302-315.

Corbin, J. M., \& Strauss, A. L. (2015). Basics of qualitative research: Techniques and procedures for developing grounded theory. Los Angeles: Sage.

Decety, J., \& Jackson, P. L. (2006). A social-neuroscience perspective on empathy. Association for Psychological Science, 15(2), 54-58.

Deveraux, C. (2017). Neuroception and attunement in Dance/Movement therapy with autism. American Journal of Dance Therapy, 39(1), 36-38.

Eberhard-Kaechele, M. (2012). Memory, metaphor and mirroring in movement therapy with trauma patients. In S. C. Koch, T. Fuchs, M. Summa, \& C. Müller (Eds.). Memory, metaphor and movement. Philapelphia, PA: John Benjamins.

Erskine, R., \& Trautmann, R. L. (1997). The process of integrative psychotherapy. 1993 In R. Erskine (Ed.). Theories and methods of an integrative transactional analysis (pp. 7995). San Francisco: TA Press.

Erskine, R. G., Moursund, J. P., \& Trautmann, R. L. (2013). Beyond empathy. A therapy of contact in relationship. Philadelphia: Brunner/Mazel.

Fischman, D. (2009). Therapeutic relationships and kinesthetic empathy. In S. Chaiklin, \& H. Wengrower (Eds.). Life is dance: The art and science of dance movement therapy (pp. 33-54). New York: Routledge.

Foster, S. (2011). Choreographing empathy: Kinesthesia in performance. New York: Routledge.

Fuchs, T. (2009). Embodied cognitive neuroscience and its consequences for psychiatry. Poiesis and Praxis, 6(3-4), 219-233.

Gallagher, S. (2005). How the body shapes the mind. Oxford: Oxford University Press.

Gallagher, S., \& Payne, H. (2015). The role of embodiment and intersubjectivity in clinical reasoning. Body, Movement and Dance in Psychotherapy, 10(1), 68-78.

Gallese, V. (2003). The roots of empathy: The shared manifold hypothesis and the neural basis of intersubjectivity. Psychopathology, 36(4), 171-180.

Gallese, V. (2005). Embodied simulation: From neurons to phenomenal experience. Phenomenology and Cognitive Sciences, 4, 23-48.

Kagan, N. (1974). Interpersonal process recall: Inquirer role and function (video). Retrieved fromMichigan: Michigan State University. https://archive.org/details/ interpersonalprocessrecallinquirerroleandfunction.

Karkou, V., \& Joseph, J. (2017). The moving and movement identities of adolescents: Lessons from dance movement psychotherapy in a mainstream secondary school. In R. Macdonald, D. J. Hargreaves, \& D. Miell (Eds.). Handbook of musical identities (pp. 232-244). United Kingdom: Oxford University Press.

Kipper, D. A., Green, D. J., \& Prorak, A. (2010). The relationship among spontaneity, impulsivity and creativity. Journal of Creativity in Mental Health, 5, 39-53.

Koch, S. C. (2006). Interdisciplinary embodiment approaches: Implications for creative arts therapies. In S. C. Koch, \& I. Brauninger (Eds.). Advances in dance/movement therapy: Theoretical perspectives and empirical findings (pp. 17-28). Berlin: Logos.

Koch, S. C., Kelbel, J., Kolter, A., Sattel, H., \& Fuchs, T. (2017). Dis-)embodiment in schizophrenia: Effects of mirroring on self-experience, empathy and wellbeing. In V. Karkou, S. Oliver, \& S. Lycouris (Eds.). The Oxford handbook of dance and wellbeing (pp. 863-881). New York: Oxford University Press.

Kossak, M. S. (2009). Therapeutic attunement: A transpersonal view of expressive art therapy. The Arts in Psychotherapy, 36, 13-18.

Laban, R. (2002). Mojstrstvo gibanja. [The mastery of movement.]. Ljubljana: Mestno gledališče ljubljansko.

Larsen, D., Flesaker, K., \& Stege, R. (2008). Qualitative interviewing using interpersonal process recall: Investigating internal experiences during professional-client conversations. International Journal of Qualitative Methods, 7(1), 18-37. Retrieved from http://www.gilis-place.com/html5/web/10286/15294ImageFile3.pdf.

Lieberman, M. D. (2007). Social cognitive neuroscience: A review of core processes. Annual Review of Psychology, 58, 259-289.

McGarry, L. M., \& Russo, F. A. (2011). Mirroring in Dance/Movement therapy: Potential mechanisms behind empathy enhancement. The Arts in Psychotherapy, 38, 178-184.

Payne, H. (2006). Dance movement therapy: Theory, research and practice. London: Routledge.

Payne, H., Warnecke, T., Karkou, V., \& Westland, G. (2016). A comparative analysis of body psychotherapy and dance movement psychotherapy from a European perspective. Body, Mind and Dance in Psychotherapy, 11(2-3), 144-166.

Rabinowitch, T., Cross, I., \& Burnard, P. (2012). Musical group interaction, intersubjectivity and merged subjectivity. In D. Reynolds, \& M. Reason (Eds.). Kinesthetic empathy in creative and cultural practices (pp. 109-120). United Kingdom: Intellect Ltd.

Reynlods, D. (2012). Mirroring movements: Empathy and social interactions. In D. Reynolds, \& M. Reason (Eds.). Kinesthetic empathy in creative and cultural practices (pp. 29-32). United Kingdom: Intellect Ltd.

Rova, M. (2017). Embodying kinaesthetic empathy through interdisciplinary practicebased research. The Arts in Psychotherapy, 55, 164-173.

Samaritter, R., \& Payne, H. (2013). Kinesthetic intersubjectivity: A dance informed contribution to self-other relatedness and shared experience in non-verbal psychotherapy with an example from autism. The Arts in Psychotherapy, 40, 143-150. 
Segal, Z. V., Williams, J. M. G., \& Teasdale, J. D. (2002). Mindfulness-based cognitive therapy for depression: A new approach to preventing relapse. New York, NY: Guilford Press.

Stern, D. (1985). The interpersonal world of the infant: A view from psychoanalysis and de velopmental psychology: With a new introduction by the author. New York: Basic Books.

Stern, D. (2004). The present moment in psychotherapy and everyday life. New York: W. W. Norton and Company Ltd.

Stolorow, R., Brandchaft, B., \& Atwood, G. (1992). Contexts of being. Hillsdale, New York:
Analytic Press.

Tortora, S. (2006). The dancing dialogue. Maryland: Paul H. Brookes Publishing Co.

Trevarthen, C., \& Fresquez, C. (2015). Sharing human movement for well-being: Research

on communication in infancy and applications in dance movement psychotherapy. Body, Movement and Dance in Psychotherapy, 10(4), 194-210.

Valdesolo, P., Ouyang, J., \& DeSteno, D. (2010). The rhythm of joint action: Synchrony promotes cooperative ability. Journal of Experimental Social Psychology, 46, 693-695. Winnicott, D. W. (1971). Playing and reality. London; New York: Routledge. 